\title{
MicroRNA-218 promotes cisplatin resistance in oral cancer via the PPP2R5A/Wnt signaling pathway
}

\author{
ZEHANG ZHUANG ${ }^{1,2}$, FENGCHUN HU ${ }^{1,3}$, JING HU $^{1,2}$, CHENG WANG $^{1,2}$, JINSONG HOU $^{1,2}$, \\ ZHIQIANG YU ${ }^{4}$, TONY T. WANG ${ }^{5}$, XIQIANG LIU ${ }^{1,2}$ and HONGZHANG HUANG ${ }^{1,2}$ \\ ${ }^{1}$ Guangdong Provincial Key Laboratory of Stomatology; ${ }^{2}$ Department of Oral and Maxillofacial Surgery, \\ Guanghua School of Stomatology, Hospital of Stomatology, Sun Yat-sen University, Guangzhou, Guangdong 510055; \\ ${ }^{3}$ Department of Stomatology, The People's Hospital of Dongying, Dongying, Shandong 257091; \\ ${ }^{4}$ School of Pharmaceutical Sciences, Southern Medical University, Guangzhou, Guangdong 510515, P.R. China; \\ ${ }^{5}$ Center for Infectious Diseases, SRI International, Harrisonburg, VA 22802, USA
}

Received October 10, 2016; Accepted April 20, 2017

DOI: $10.3892 / o r .2017 .5899$

\begin{abstract}
Accumulating data suggest that microRNAs (miRNAs) play a pivotal role in the regulation of tumor cell sensitivity to chemotherapeutic agents. Although the roles of a few miRNAs have been identified in cisplatin resistance, little is known in regards to the concerted contribution of miRNA-mediated biological networks. In the present study, we demonstrated that microRNA-218 (miR-218) was significantly upregulated in cisplatin-resistant oral cancer cells. The results of cell viability and apoptosis assay showed that ectopic expression of miR-218 induced cell survival and resistance to cisplatin, whereas suppression of miR-218 caused apoptosis and enhanced sensitivity to cisplatin. Moreover, we identified PPP2R5A as a new direct target of miR-218 by using the dual luciferase reporter assay. Overexpression of miR-218 led to inhibition of PPP2R5A expression, whereas knockdown of miR-218 increased PPP2R5A levels. Introduction of PPP2R5A abrogated miR-218-mediated cell survival and drug resistance. Furthermore, suppression of miR-218 or PPP2R5A significantly promoted or reduced cisplatin-induced apoptosis, respectively. Finally, PPP2R5A overexpression or $\beta$-catenin knockdown inhibited miR-218-mediated Wnt activation and partially restored cell sensitivity. Our data revealed a molecular link
\end{abstract}

Correspondence to: Professors Xiqiang Liu or Hongzhang Huang, Department of Oral and Maxillofacial Surgery, Guanghua School of Stomatology, Hospital of Stomatology, Sun Yat-sen University, Guangzhou, Guangdong 510055, P.R. China

E-mail: xiqiangliu@aliyun.com

E-mail: drhuang52@163.com

Abbreviations: miR-218, microRNA-218; 3'UTR, 3' untranslated region; PPP2R5A, protein phosphatase 2 regulatory subunit $\mathrm{B}-\alpha$; GSK $3 \beta$, glycogen synthase kinase $3 \beta$; TopoII $\beta$, topoisomerase II $\beta$

Key words: miR-218, oral cancer, PPP2R5A, Wnt signaling pathway, cisplatin, chemoresistance between miR-218 and PPP2R5A/Wnt signaling and implicates miR-218 as a potential target for oral cancer therapy.

\section{Introduction}

Oral cancer is one of the most common malignancies worldwide. For patients with locally advanced or metastatic stages, chemotherapy is recommended as the standard therapy. Cisplatin alone or cisplatin-based chemotherapy or concurrent radiochemotherapy remains the first choice for the treatment of advanced stage cancers, in particular unresectable tumors (1). Unfortunately, acquired or intrinsic tumor resistance to cisplatin therapy greatly hampers its therapeutic efficacy (2). Several genes and pathways involved in apoptosis, drug efflux, growth, proliferation and angiogenesis appear to influence sensitivity to cisplatin $(3,4)$, but overcoming drug resistance in patients remains a challenge. Understanding the molecular mechanisms underlying cisplatin resistance is essential for solving this problem.

Recently, mounting evidence has demonstrated that microRNAs (miRNAs) play a role in chemoresistance (5-7). For example, overexpression of miR-21 suppresses PDCD4, TPM1 and PTEN expression and induces cisplatin resistance, representing a poor prognosis in tongue cancer $(8,9)$. Upregulation of miR-200b and miR-15b reverses epithelial-to-mesenchymal transition in chemoresistant tongue cancer cells by inhibiting BMI1 (10). However, the role of miRNAs in oral cancer cell resistance to chemotherapy is not fully understood and necessitates further investigation.

MicroRNA-218 (miR-218) is an intronic miRNA that is coexpressed with its host genes: tumor suppressor genes SLIT2/3 (11). Evidence suggests that miR-218 is frequently downregulated in various solid tumors and functions as a tumor suppressor (12-16). Concordantly, decreased miR-218 expression has been found to correlate with a poor prognosis in non-small cell lung cancer (NSCLC) (17), cervical (18) and oral cancer (19). Moreover, reduced miR-218 levels have been detected in chemoresistant cancer cells, and restoration of miR-218 expression can sensitize cells to chemotherapeutic agents including cisplatin $(20,21)$ and carboplatin $(22)$. 
Conversely, increased expression of miR-218 has been reported in acute lymphocytic leukemia (ALL) (23), glioma (24) and metastatic breast cancer (25). A recent study also showed higher expression levels of plasma miR-218 in advanced NSCLC patients with epidermal growth factor receptor (EGFR) mutation, suggesting a potential role of this miRNA in primary resistance to epidermal growth factor receptor tyrosine kinase inhibitor (EGFR-TKI) in advanced NSCLC patients with EGFR mutation (26). These contradictory findings indicate the complex function of miR-218 in mediating networks in tumorigenesis and progression.

Dysregulation of the Wnt signaling pathway plays a key role in cancer chemoresistance. Hassan et al found that miR-218 activates the Wnt pathway by downregulating its inhibitors sclerostin (SOST), Dickkopf2 (DKK2) and secreted frizzled-related protein 2 (SFRP2), thus, promoting osteomimicry of metastatic breast cancer cells (25). Protein phosphatase $2 \mathrm{~A}$ (PP2A) and its B56 subunit $\alpha$ (encoded by the PPP2R5A gene) has been reported to control cell growth and division in several critical pathways, including the Wnt pathway (27). PP2A was originally thought to be a tumor suppressor in Wnt signaling by negatively regulating $\beta$-catenin and GSK3 $\beta(28,29)$. However, the precise biological function of PP2A, as well as PPP2R5A in cancer progression and chemoresistance, remains elusive. In the present study, we found that miR-218 expression was upregulated in cisplatin-resistant oral cancer cell lines and tissues. Furthermore, downregulation of miR-218 inhibited Wnt signaling in oral cancer cells and sensitized tumor cells to cisplatin-induced apoptosis by targeting PPP2R5A.

\section{Materials and methods}

Patients and specimens. After obtaining written informed consent, human oral cancer tissues $(n=61)$ were collected from patients undergoing standard surgical procedures at The Affiliated Stomatological Hospital of Sun Yat-sen University (Guangzhou, China) between January 2008 and December 2012. The diagnosis was based on pathological evidence, and the specimens were immediately snap-frozen in liquid nitrogen. All patients received cisplatin-based neoadjuvant chemotherapy before surgical excision. The study protocol was approved by the Ethics Committee of The Affiliated Stomatological Hospital of Sun Yat-sen University.

Cell lines and culture. Human oral cancer UM1, UM2, Cal27 and MD1386Ln cell lines were provided by Dr Zhou, University of Illinois at Chicago (Chicago, IL, USA). SCC9, SCC15 and SCC25 cell lines were obtained from the American Type Culture Collection (ATCC; Manassas, VA, USA). The Tca8113 cell line was obtained from the Chinese Oral Tissue Culture and Collection Center (Shanghai, China). The cells were maintained in Dulbecco's modified Eagle's medium (DMEM)/F12 (Life Technologies, Carlsbad, CA, USA) supplemented with $10 \%$ fetal bovine serum (FBS) and $1 \%$ penicillin/streptomycin (Gibco, Grand Island, NY, USA) in a humid atmosphere containing $5 \% \mathrm{CO}_{2}$ at $37^{\circ} \mathrm{C}$.

Reagents and antibodies. cis-Diammineplatinum (II) dichloride was purchased from Sigma-Aldrich (St. Louis, MO, USA; P/N: P4394). Antibodies against $\beta$-catenin,
GSK3 $\beta$ and $\beta$-tubulin were purchased from Cell Signaling Technology, Inc. (Danvers, MA, USA). The antibody against PPP2AB56 $\alpha$ was purchased from ProteinTech (Chicago, IL, USA) (P/N: 12675-2-AP). Antibodies against MRP1, ABCG2, $\mathrm{P}$-glycoprotein and topoisomerase II $\beta$ were obtained from Abcam (Cambridge, MA, USA). The antibody against EZH2 was purchased from OriGene (Rockville, MD, USA).

Cell transfection. miR-218 mimic (P/N: miR10000275) and inhibitor (anti-miR-218; P/N: miR20000275), PPP2R5A siRNA (P/N: stQ0004381-1) and $\beta$-catenin siRNA (P/N: stQ0002532-1) were obtained from RiboBio (Guangzhou, China). Cells were plated and cultured for $24 \mathrm{~h}$ and transfected with miR-218 mimic $(20 \mathrm{nM})$, anti-miR-218 $(50 \mathrm{nM})$ or siRNAs $(50 \mathrm{nM})$. The transfection was performed using Lipofectamine RNAi Max (Invitrogen, Carlsbad, CA, USA). Lentiviral PPP2R5A (LV-PPP2R5A) and empty lentiviral vector (LV-NC) were designed and constructed by GenePharma Co., Ltd. (Shanghai, China), and they were transfected into tumor cells according to the manufacturer's instructions.

Quantitative real-time reverse transcription-PCR. Total RNA was isolated from oral cancer tissues or cells using TRIzol reagent (Invitrogen). miR-218 was quantified using the mirVana $^{\mathrm{TM}}$ qRT-PCR miRNA detection kit (Ambion) as previously described (Liu et al, 2009) according to the manufacturer's instructions. Human U6 rRNA served as an internal control. To determine the relative mRNA levels of PPP2R5A and GAPDH (used as an internal control), $1 \mu \mathrm{g}$ of total RNA was subjected to reverse transcription using a PrimeScript RT reagent kit (Takara Bio, Shiga, Japan). Real-time PCR was performed using a quantitative 2-step RT-PCR assay (Roche Diagnostics, Basel, Switzerland) according to the standardized protocol. The sequences of the specific primers for mRNA amplification were as follows: PPP2R5A forward primer, 5'-CTAGTCCCTCCTGACCCA-3' and reverse primer, 5'-TAAATGCTGCTCAATCCC-3'; GAPDH forward primer, 5'-AACGGATTTGGTCGTATTG-3' and reverse primer, 5'-GGAAGATGGTGATGGGATT-3'. The thermal cycling parameters were as follows: pre-incubation at $95^{\circ} \mathrm{C}$ for $5 \mathrm{~min}$, followed by 40 cycles of amplification $\left(95^{\circ} \mathrm{C}\right.$ for $10 \mathrm{sec}$, $60^{\circ} \mathrm{C}$ for $20 \mathrm{sec}$, and $72^{\circ} \mathrm{C}$ for $\left.20 \mathrm{sec}\right)$, melting curve $\left(95^{\circ} \mathrm{C}\right.$ for $5 \mathrm{sec}, 65^{\circ} \mathrm{C}$ for $1 \mathrm{~min}$, and $\left.97^{\circ} \mathrm{C}\right)$, and cooling $\left(40^{\circ} \mathrm{C}\right.$ for $\left.10 \mathrm{sec}\right)$. The relative expression level was computed using the $2^{-\Delta \Delta \mathrm{Ct}}$ analysis method. All qRT-PCR reactions were evaluated in triplicate. All primers were ordered from Invitrogen.

Cell viability assay. Cell viability was measured using a tetrazolium salt-based Cell Counting Kit-8 assay (CCK-8; Dojindo Laboratories, Kumamoto, Japan) according to the manufacturer's protocol. Briefly, the cells $\left(5 \times 10^{3} /\right.$ well) were seeded in 96-well plates and allowed to attach overnight. They were then cultured in fresh medium containing different concentrations of cisplatin $(0,0.25,0.5,1,2,4,8,16$ and $32 \mu \mathrm{g} /$ $\mathrm{ml})$. After incubation for another $72 \mathrm{~h}, 10 \mu \mathrm{l}$ of CCK-8 solution was added to each well and incubated at $37^{\circ} \mathrm{C}$ for $2 \mathrm{~h}$. The absorbance of each well was assessed on a microplate reader (Tecan GENios, Zurich, Switzerland) at $450 \mathrm{~nm}$. Cell viability was calculated as the ratio of each treatment group to the untreated control group. The $\mathrm{IC}_{50}$ values were determined as 
A

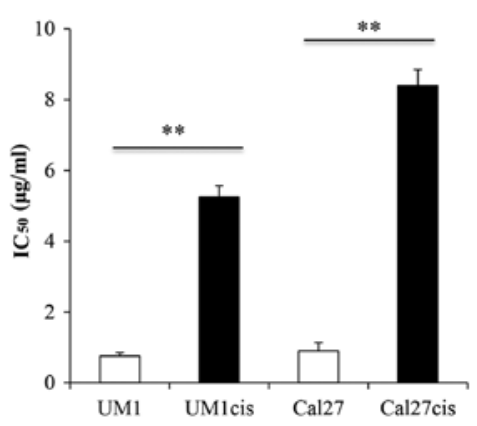

B

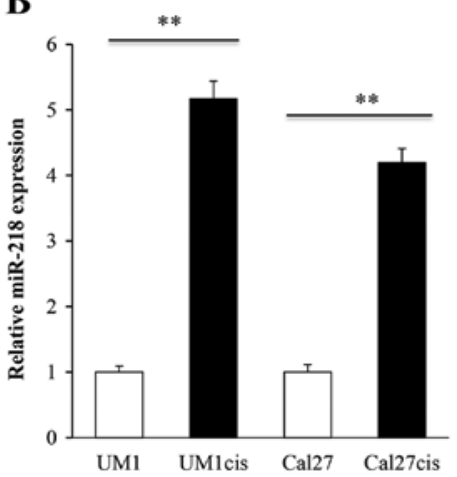

C

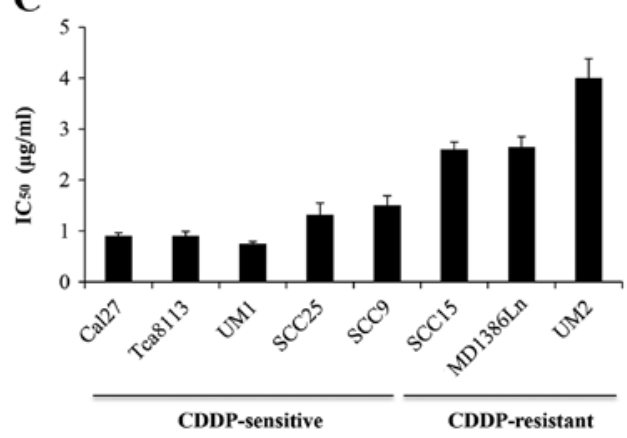

D

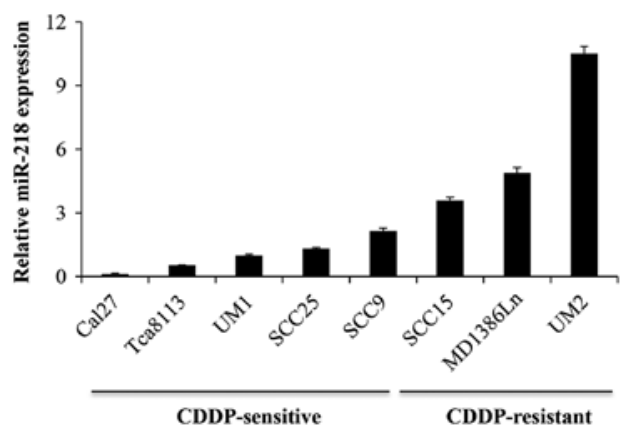

Figure 1. Expression of miR-218 is upregulated in cisplatin-resistant oral cancer cells. (A) $\mathrm{IC}_{50}$ values for cisplatin in oral cancer cisplatin-resistant cell lines (UM1cis, Cal27cis) and their parental cell lines (UM1, Cal27) were determined by CCK-8 assay. (B) The expression level of miR-218 was higher in cisplatin-resistant cell lines (UM1cis, Cal27cis) compared with that in their parental cell lines (UM1, Cal27). (C) IC $\mathrm{I}_{50}$ values for cisplatin in oral cancer cell lines were determined using the CCK-8 assay. (D) qRT-PCR analysis of miR-218 expression was conducted in a panel of 8 oral cancer cell lines. Quantification analysis was applied to identify the relative level of miR-218 in comparison to U6, which served as an internal control. The results are the mean \pm SD of repeated independent experiments; ${ }^{* *} \mathrm{P}<0.01$, compared with the control.

the concentration resulting in a $50 \%$ reduction in cell viability compared with the control. All experiments were performed 3 times in quadruplicate.

Cell apoptosis assay. Cells were grown in 6-well plates, transfected with the desired reagents for $48 \mathrm{~h}$ and treated with cisplatin after transfection. After treatment for $48 \mathrm{~h}$, the cells were collected, washed with ice-cold phosphate-buffered saline (PBS) twice and gently resuspended in $1 \mathrm{X}$ binding buffer. After addition separately of $5 \mu \mathrm{l}$ of Annexin V-FITC and $10 \mu \mathrm{l}$ of propidium iodide, the cells were gently vortexed and incubated for $5 \mathrm{~min}$ in the dark. Flow cytometry (FACScan; Beckman Coulter, Brea, CA, USA) was used to assess apoptotic cells. Apoptotic cells were quantified using CellQuest software.

Western blot analysis. Total cell lysates were prepared using RIPA lysis buffer (50 mM Tris- $\mathrm{HCl} \mathrm{pH} 7.4,10 \mathrm{mM} \mathrm{NaCl}, 1 \%$ NP- $40,0.5 \%$ sodium deoxycholate and $0.1 \%$ SDS). The protein concentration was measured using the BCA method (Beyotime, Beijing, China). Proteins were resolved by SDS-PAGE (10\% gel) and subjected to immunoblot analysis using antibodies against MRP1 (1:1,000), ABCG2 (1:1,000), P-glycoprotein $(1: 500)$, topoisomerase II $\beta(1: 1,000)$, EZH $2(1: 1,000), \beta$-catenin $(1: 1,000)$, GSK3 $\beta(1: 1,000), \beta$-tubulin $(1: 2,000)$ or PPP2AB56 $\alpha$ $(1: 1,000)$. The membrane was further probed with horseradish peroxidase-conjugated goat anti-rabbit $\operatorname{IgG}(1: 1,000$ dilution; Beyotime) or goat anti-mouse IgG (1:1,000; Cell Signaling
Technology, Inc.), and the bands were visualized using a Novex ECL HRP chemiluminescent substrate reagent kit (Invitrogen). The protein bands were quantified using Alpha Innotech imaging software (San Leandro, CA, USA).

Dual luciferase reporter assay. A 55-bp fragment from the 3' untranslated region ( 3 'UTR) of the PPP2R5A gene (position 2586 to 2640; NM_006243.3) containing the miRNA-218 binding site was cloned into the $\mathrm{XbaI}$ site of the pGL3 firefly luciferase reporter vector (Promega, Madison, WI, USA). A corresponding mutant construct was created by mutating the seed region of the miR-218 binding site. The constructs were then verified by sequencing. Cells were transfected with the reporter constructs containing the targeting sequence from the PPP2R5A 3'UTR (named pGL-PPP2R5A WT) or its mutant (named pGL-PPP2R5A Mut) using Lipofectamine 2000 (Invitrogen). The pRL-TK vector (Promega) was co-transfected as an internal control for normalization of the transfection efficiency. The luciferase activities were then determined as previously described (30) using a Lumat LB 9507 luminometer (Berthold Technologies GmbH \& Co. KG, Bad Wildbad, Germany).

Statistical analysis. All numerical data are presented as the mean \pm standard deviation (SD), and all error bars represent the SD of the mean. The Student's t-test and one-way analysis of variance (ANOVA) were used to determine differences. The Chi-square or Fisher's exact tests were used to analyze the 
A

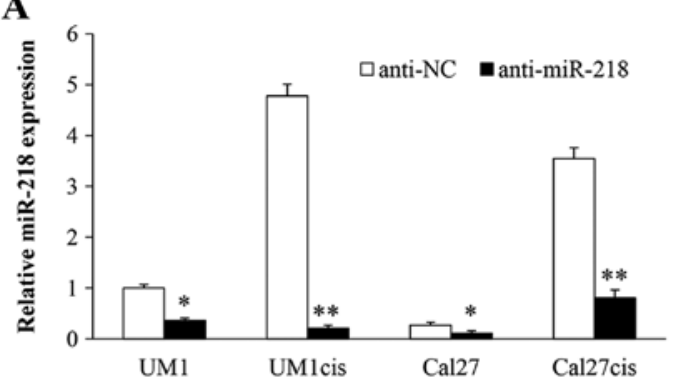

C

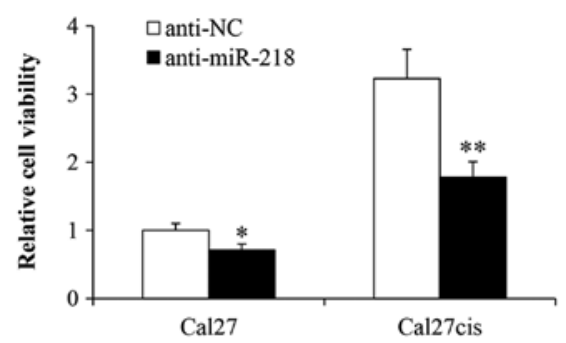

$\mathbf{E}$

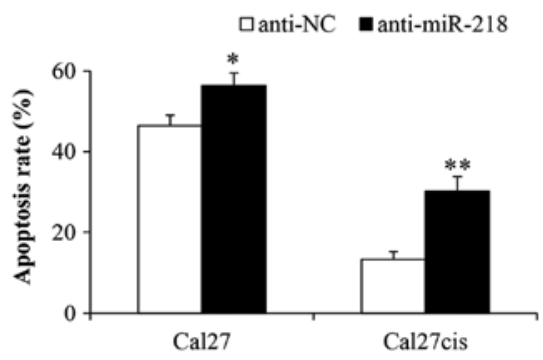

B

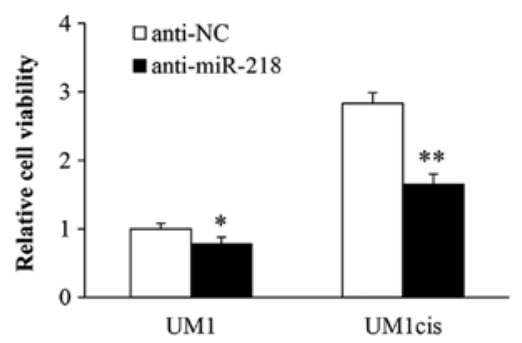

D

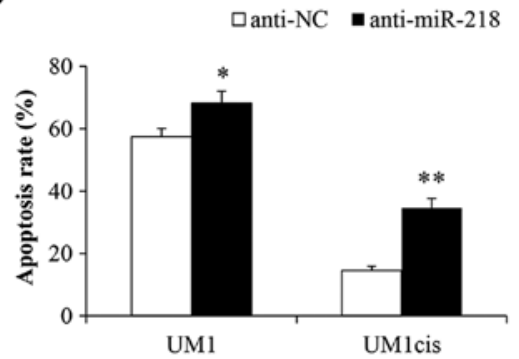

F

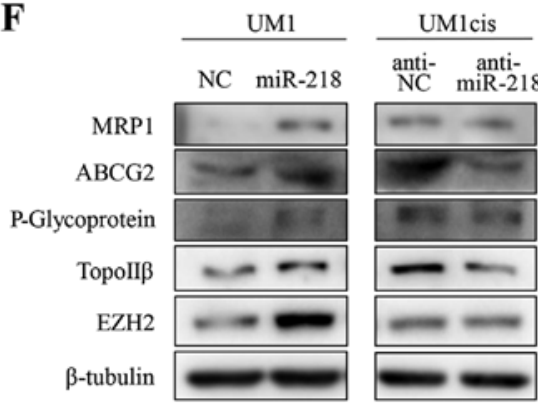

G

口UM1 NC घUM1 miR-218 aUMlcis anti-NC \$UMlcis anti-miR-218

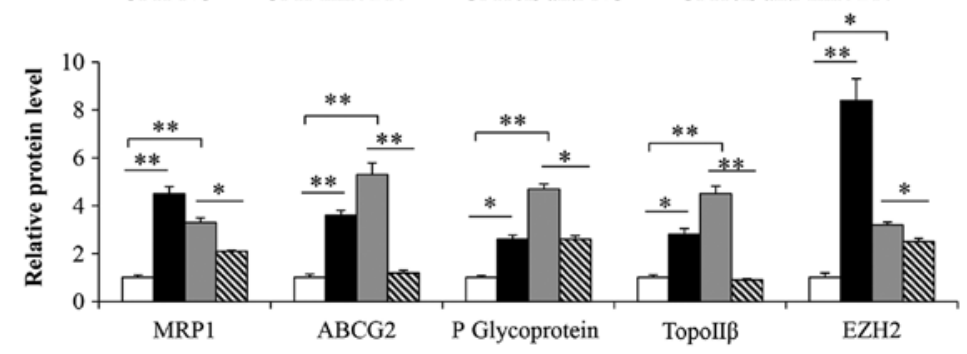

Figure 2. Suppression of miR-218 promotes cisplatin sensitivity in resistant oral cancer cells. (A) The tumor cells were transfected with anti-miR-218 or its control (anti-NC), and total RNA was extracted for qRT-PCR. (B and C) UM1 and Cal27 cells transfected with anti-miR-218 or its control were treated with cisplatin $(2.5 \mu \mathrm{g} / \mathrm{ml})$. The cell viability was assayed using the CCK-8 method. (D and E) Apoptosis was quantitated by flow cytometry. (F) The protein expression levels of chemoresistance-related proteins, including EZH2, ABCG2, MRP1, P-glycoprotein and TopoII $\beta$, were determined by western blotting. $\beta$-tubulin served as a loading control. (G) The expression levels of the chemoresistance-related proteins were quantitated. Data represent the mean \pm SD of 3 independent experiments; ${ }^{*} \mathrm{P}<0.05,{ }^{* *} \mathrm{P}<0.01$.

association between miR-218 and PPP2AB56 $\alpha$ expression. All statistical analyses were performed using SPSS 16.0 software. A P-value $<0.05$ was considered significant.

\section{Results}

miR-218 expression is upregulated in cisplatin-resistant oral cancer cells. First, we determined whether upregulation of miR-218 expression was a common feature of cisplatinresistant oral cancer cells. UM1 and Cal27 cells, both of which are sensitive to cisplatin (cisplatin $\mathrm{IC}_{50}$ values of 0.75 and $0.9 \mu \mathrm{g} / \mathrm{ml}$, respectively), were continuously exposed to a gradient concentration of cisplatin for $\sim 6$ months until the cells acquired cisplatin resistance. Cell viability was determined using the CCK- 8 assay in cell lines exposed to increasing concentrations of CDDP for $48 \mathrm{~h}$. As illustrated in Fig. 1A, UM1cis and Cal27cis cells were more resistant to cisplatin than the parental cell lines, with $\mathrm{IC}_{50}$ values of 5.23 and $8.42 \mu \mathrm{g} / \mathrm{ml}$, respectively, which were $\sim$ - and 9-fold higher than the $\mathrm{IC}_{50}$ values for UM1 and Cal27. miR-218 
A

Position 2586-2640 of PPP2R5A 3'UTR
miR-218 3'--- UGUACCAAUCUAGUUCGUGUU 5'
PPP2R5A 5'--- UCCAGGCUUUUUAAAGCACAA 3'UTR

B

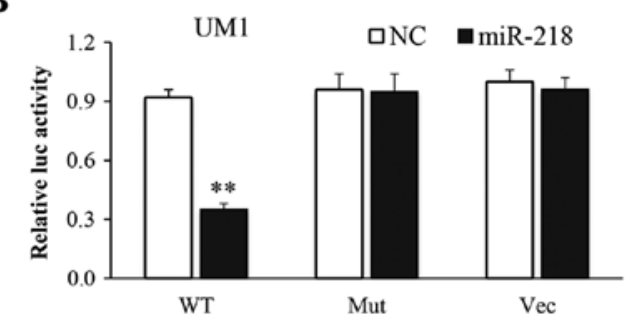

C

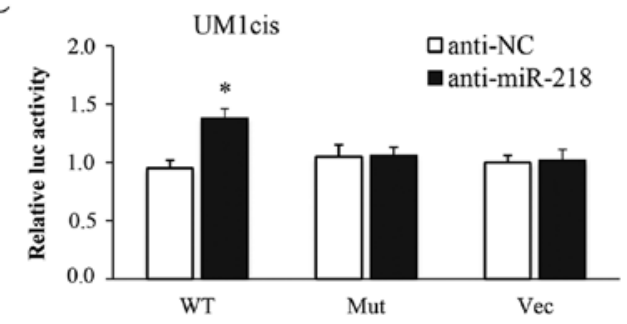

D

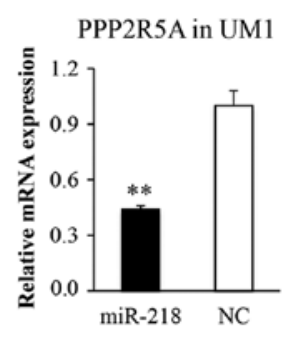

$\mathbf{E}$

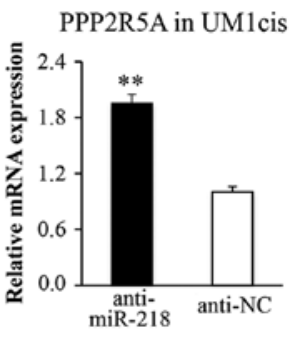

F
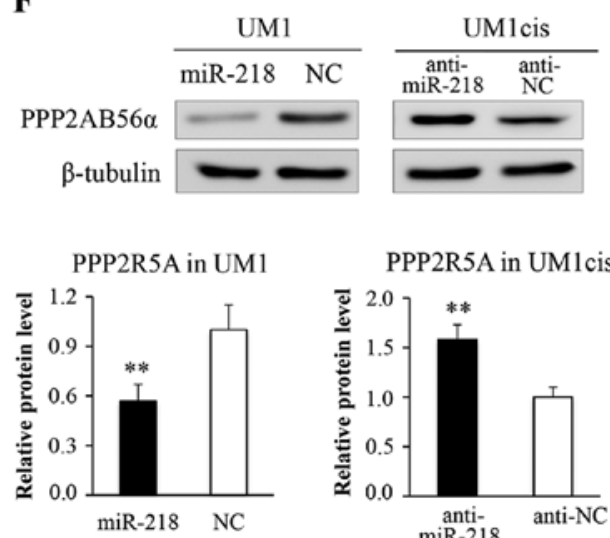

PPP2R5A in UM1cis

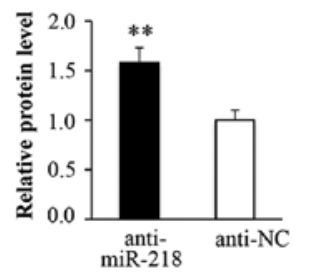

Figure 3. PPP2R5A is a novel target of miR-218. (A) The predicted miR-218 binding site in the 3'UTR of PPP2R5A. (B) Luciferase reporter assay using UM1 cells cotransfected with wild-type (WT) or mutant (Mut) 3'UTR (50 ng) and miR-218 or miR-control (NC). (C) Luciferase reporter assay using UM1cis cells cotransfected with WT or Mut 3'UTR (50 ng) and anti-miR-218 or its control (anti-NC). The pRL-TK vector was cotransfected as an internal control to normalize the transfection efficiency. (D) The effect of miR-218 on the mRNA expression level of PPP2R5A in UM1 cells was tested by qRT-PCR. (E) The effect of anti-miR-218 on the mRNA expression of PPP2R5A in UM1cis cells was tested by qRT-PCR. (F) Lysates from UM1 and UM1cis cells after transfection for $48 \mathrm{~h}$ with miR-218 or anti-miR-218 were analyzed by western blotting to evaluate PPP2R5A expression. $\beta$-tubulin served as a loading control. Data represent the mean $\pm \mathrm{SD}$ from 3 independent experiments; ${ }^{*} \mathrm{P}<0.05,{ }^{* *} \mathrm{P}<0.01$.

expression was determined by quantitative real-time RT-PCR in cisplatin sensitive and resistant UM1 and Cal27 cells. As shown in Fig. 1B, cisplatin-sensitive cells expressed lower levels whereas cisplatin-resistant cell lines exhibited markedly increased levels of miR-218. Next, we investigated the endogenous miR-218 expression in an oral cancer cell line panel. As expected, the levels of miR-218 were significantly lower in CDDP-sensitive cell lines compared with CDDP-resistant cell lines (Fig. 1C and D). To confirm these results, we used oral cancer tissues from chemosensitive and non-sensitive patients and compared the expression profiles of miR-218. Chemosensitive or non-sensitive was determined based on the clinical assessment of patients treated with cisplatin-based neoadjuvant chemotherapy; those with a good therapeutic outcome were classified as sensitive, others were non-sensitive. It was found that miR-218 was increased in the non-sensitive oral cancers $(4.16 \pm 0.51$ vs. $1.38 \pm 0.25 ; \mathrm{P}<0.05$, data not shown).

Downregulation of miR-218 increases the sensitivity of oral cancer cells to cisplatin. To determine whether the modulation of miR-218 levels influences the response to cisplatin, we suppressed miR-218 expression in cisplatin-resistant cell lines by transfecting cells with anti-miR-218 (Fig. 2A). Both UM1 and Cal27 cells became more sensitive to cisplatin compared with the negative control group (Fig. 2B and C). In addition, a marked increase in apoptosis was observed in the anti-miR-218-transfected cells (Fig. 2D and E). No significant difference between the mock and the negative control group were found (data not shown). Furthermore, we also detected the expression levels of chemoresistance-related proteins. As expected, increased protein levels of MRP1, ABCG2, P-glycoprotein, topoisomerase II $\beta$ (TopoII $\beta$ ) and EZH2 were found in the UM1cis cell line compared to the parental cell line UM1 (Fig. 2F and G). However, levels of these proteins were reduced when UM1cis cells were transfected with antimiR-218 compared with levels in the anti-NC-transfected cells, whereas levels were increased in the UM1 cells transfected with the miR-218 mimic (Fig. 2F and G). These results indicate that miR-218 expression induces oral cancer resistance to cisplatin treatment.

PPP2R5A is a direct target of miR-218 in oral cancer cells. To explore the potential target through which miR-218 induces cisplatin resistance in oral cancer cells, we predicted putative miR-218 targets using miRWalk, PicTar, TargetScan and miRanda. Our analysis identified PPP2R5A, a key subunit of PP2A, as a candidate miR-218 target (Fig. 3A). The putative targeted sequence found in the PPP2R5A 3'UTR [wild-type, (WT)] or the mutant sequence [mutant type (MUT)] was cloned into the luciferase reporter plasmid, respectively. Our results showed that miR-218 reduced the luciferase activity in the reporter construct containing wild-type PPP2R5A, but not the mutant 3'UTR in UM1 cells (Fig. 3B). Furthermore, the luciferase activity of the construct containing the wild-type 3'UTR, but not the mutant 3'UTR was increased in the UM1cis 
A

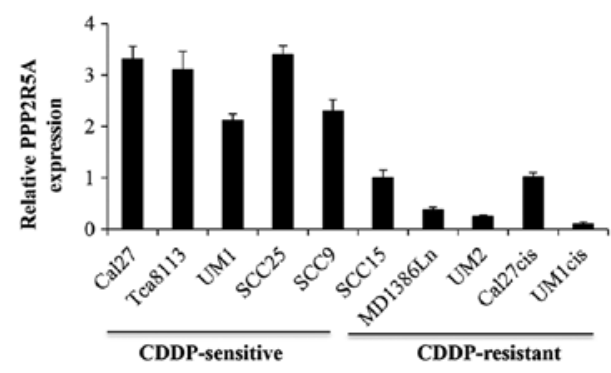

C
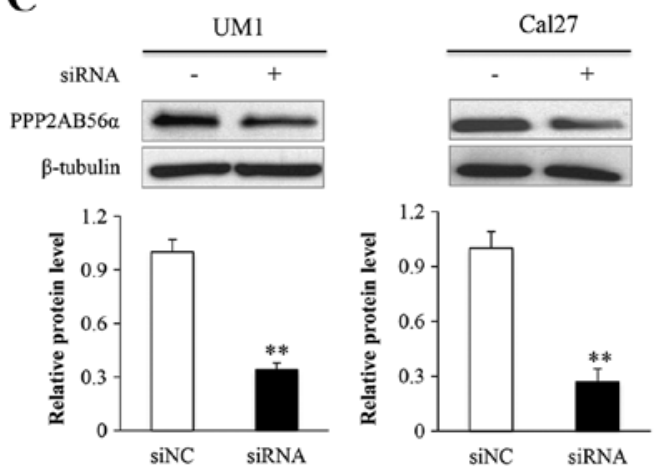

E

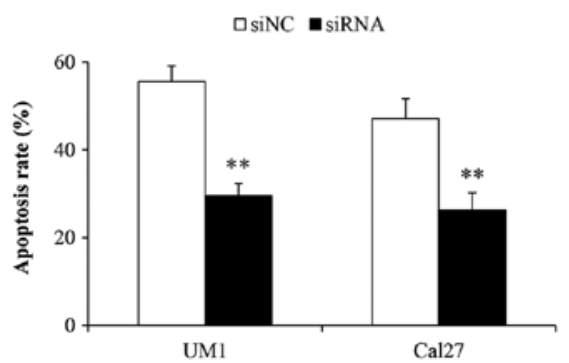

B

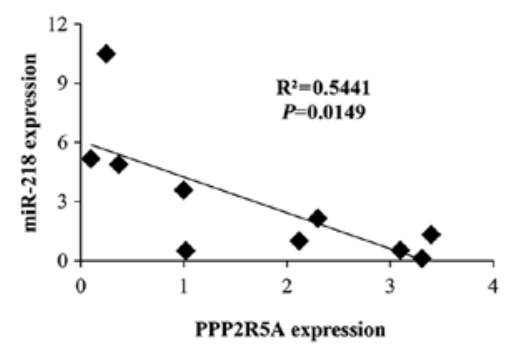

D
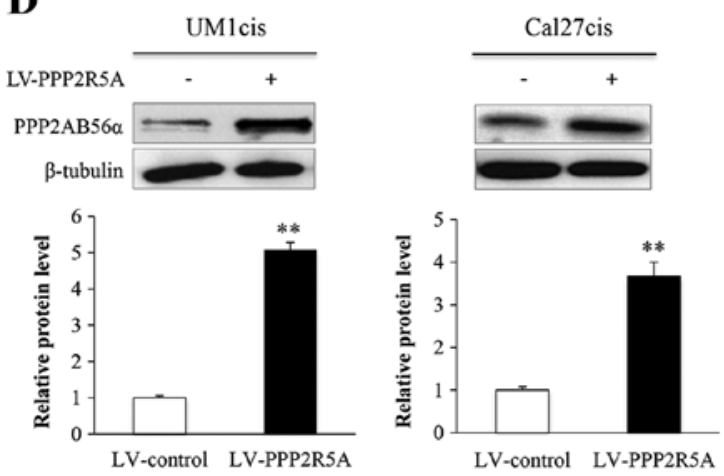

F

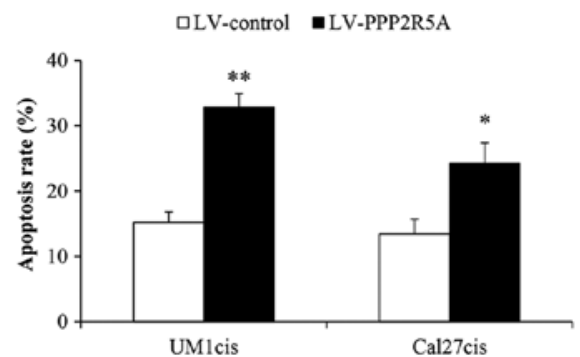

Figure 4. PPP2R5A affects cisplatin treatment sensitivity in oral cancer cells. (A) qRT-PCR analysis of PPP2R5A expression was conducted in oral cancer cell lines. (B) A reverse correlation between PPP2R5A mRNA and miR-218 expression in oral cancer cell lines was observed. (C) UM1 and Cal27 cells were transfected with siRNA against PPP2R5A or its control (siNC), and total protein was extracted for immunoblotting (upper panel). The expression level of PPP2AB56 $\alpha$ was quantitated (lower panel). (D) UM1cis and Cal27cis cells were infected with LV-PPP2R5A or its control (LV-control), and immunoblotting was performed and quantitated. The tumor cells were transfected with siRNA against (E) PPP2R5A or (F) LV-PPP2R5A and treated with cisplatin (2.5 $\mu \mathrm{g} / \mathrm{ml})$, and the apoptosis rate was quantitated by flow cytometry. Data represent the mean $\pm \mathrm{SD}$ of 3 independent experiments; ${ }^{*} \mathrm{P}<0.05,{ }^{* *} \mathrm{P}<0.01$.

cells transfected with anti-miR-218 (Fig. 3C). The cells were further transfected with miR-218 or anti-miR-218 and were examined for PPP2R5A expression by qRT-PCR and western blot analysis. As shown in Fig. 3D and F, miR-218 transfection led to an obvious decrease in PPP2R5A mRNA and protein expression. Conversely, anti-miR-218 transfection significantly increased the expression level of PPP2R5A (Fig. 3E and F). These data confirmed that PPP2R5A is a direct target of miR-218 and may contribute to the effect of miR-218 on oral cancer chemoresistance.

PPP2R5A renders oral cancer cells more sensitive to cisplatin. To determine whether the expression levels of PPP2R5A influence the cisplatin response of oral cancer cells, we investigated the endogenous PPP2R5A expression in an oral cancer cell line panel. As shown in Fig. 4A, the levels of PPP2R5A were significantly higher in the CDDP-sensitive cell lines compared with levels in the CDDP-resistant cell lines. Moreover, a negative correlation between expression of PPP2R5A and miR-218 was identified ( $\mathrm{P}=0.0149$; Fig. 4B). Then, the UM1 and Cal27 cells were transfected with an siRNA against PPP2R5A or its control (siNC) and PPP2R5A protein (PPP2AB56 $\alpha$ ) was knocked down (Fig. 4C). Alternatively, UM1cis and Cal27cis cells were infected with lentiviruses expressing PPP2R5A (LV-PPP2R5A) or its control (LV-control) and PPP2AB56 $\alpha$ was indeed overexpressed (Fig. 4D). The treated UM1, UM1cis, Cal27 and Cal27cis cells were further exposed to cisplatin to assess cell apoptosis. The results showed that suppression of PPP2R5A inhibited apoptosis in the sensitive cells (Fig. 4E), and overexpression of PPP2R5A induced apoptosis in the resistant cells (Fig. 4F).

miR-218 induces cisplatin resistance in oral cancer cells by targeting PPP $2 R 5 A$. To further explore whether miR-218 plays a role as an oncomiR through PPP2R5A, we evaluated the expression of PPP2R5A protein and its correlation 


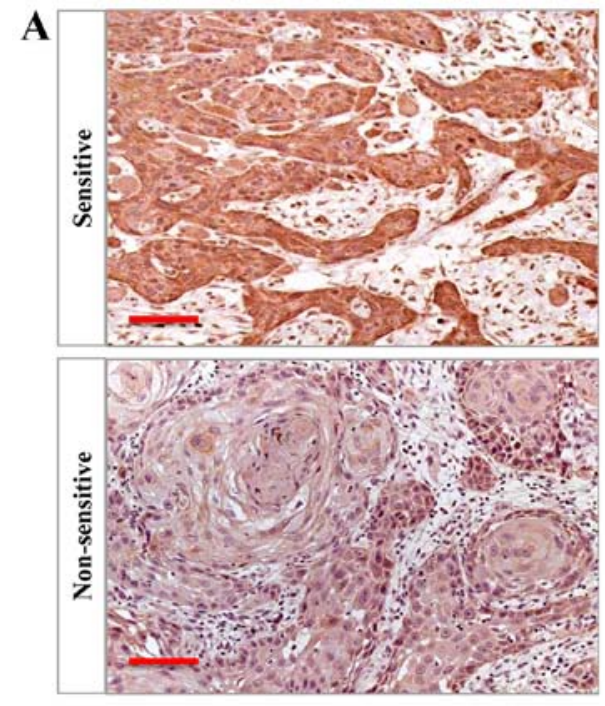

\begin{tabular}{ccccc}
\hline \multirow{2}{*}{ Group } & $\mathrm{N}$ & \multicolumn{2}{c}{ PP2AB56 $\alpha$ expression } & \multirow{2}{*}{ P-value } \\
\cline { 3 - 4 } & & High & Low & \\
\hline Sensitive & 35 & 20 & 15 & 0.019 \\
Non-sensitive & 26 & 7 & 19 & \\
\hline
\end{tabular}

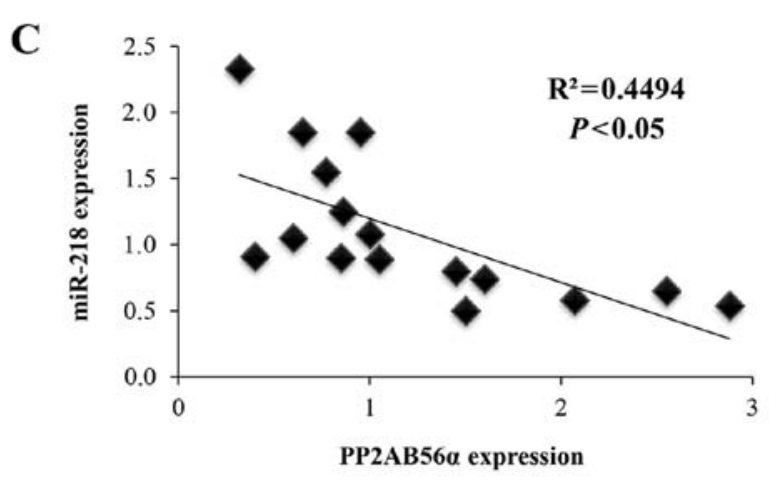

Figure 5. PPP2R5A protein expression and its correlation with miR-218 in oral cancer tissues. (A) The protein expression of PPP2R5A was examined in primary tumors from patients with oral cancer who received chemotherapy prior to surgery and had a sensitive or non-sensitive outcome by immunohistochemistry. Scale bar, $100 \mu \mathrm{m}$. (B) The expression of PPP2R5A protein in chemosensitive tissues was higher than that in tissues with failure of chemotherapy (C) A reverse correlation between PPP2R5A protein and miR-218 expression was observed.

A

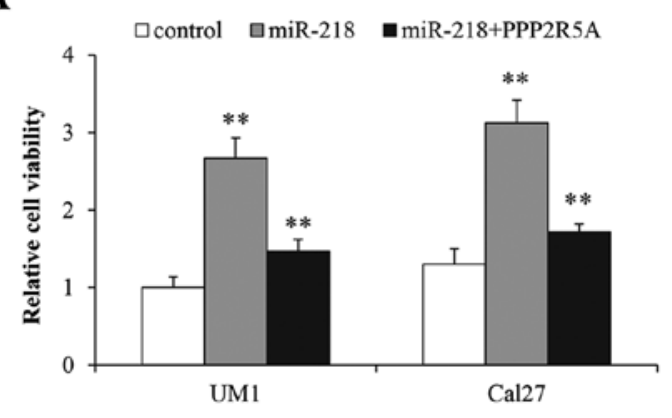

C

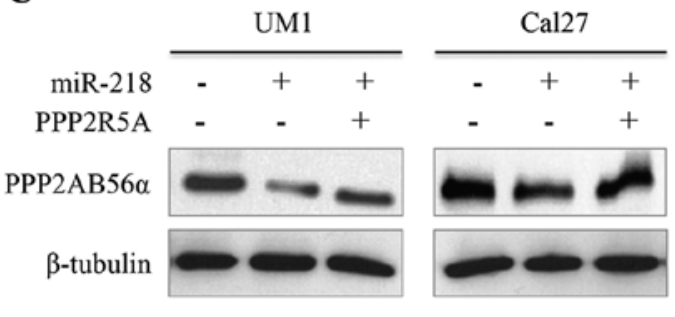

B
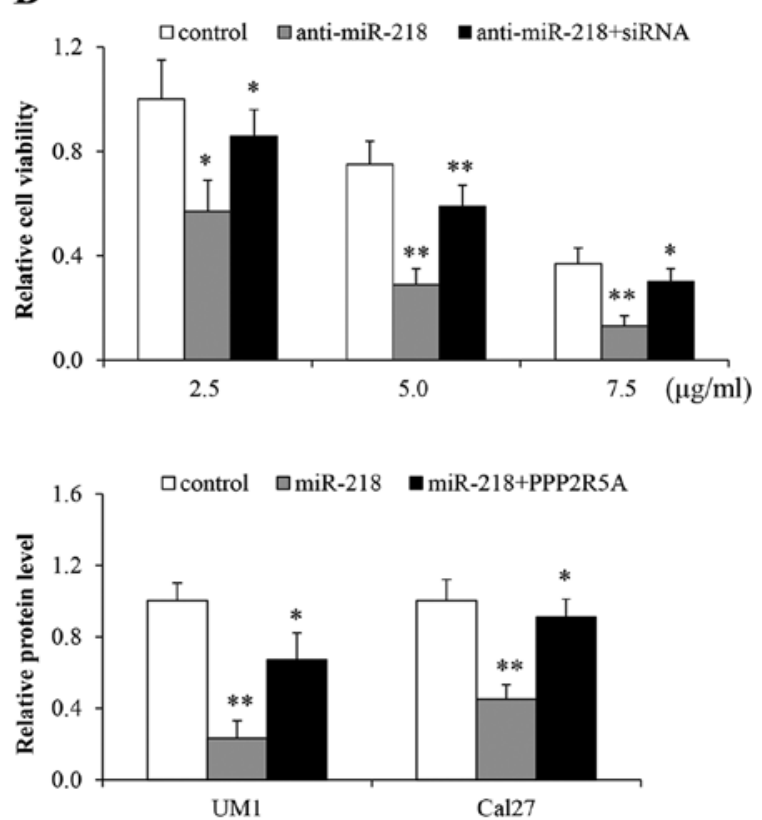

Figure 6. miR-218 affects chemoresistance by downregulating PPP2R5A. (A) UM1 and Cal27 cells transfected with miR-218, PPP2R5A or control were treated with cisplatin $(2.5 \mu \mathrm{g} / \mathrm{ml})$. The cell viability was assayed using the CCK-8 assay. (B) UM1cis cells were transfected with anti-miR-218, siRNA against PPP2R5A or negative control for $24 \mathrm{~h}$, and then treated with a gradient concentration of cisplatin. The CCK-8 assay was performed $48 \mathrm{~h}$ after treatment. (C) Western blotting was used to detect PPP2AB56 $\alpha$ protein (left panel). The expression level of PPP2AB56 $\alpha$ was quantitated (right panel). Data represent the mean $\pm \mathrm{SD}$ of 3 independent experiments; ${ }^{*} \mathrm{P}<0.05,{ }^{* *} \mathrm{P}<0.01$.

with miR-218 expression in human oral cancer tissues. As expected, PPP2AB56 $\alpha$ was upregulated in chemosensitive oral cancer tissues (Fig. 5A and B). Furthermore, a reverse correlation between PPP2AB56 $\alpha$ and miR-218 expression was noted (Fig. 5C). Next, we performed rescue experiments to validate that PPP2R5A targeting is involved in miR-218-mediated drug resistance. To achieve this aim, UM1 and Cal27 cells were infected with miR-218 mimics or combined with LV-PPP2R5A, and cell viability was analyzed using the CCK- 8 assay. It was found that miR-218 enhanced cell viability, and LV-PPP2R5A coexpression partially abrogated miR-218-induced cell growth (Fig. 6A). In contrast, cell viability results showed that anti-miR-218 could restore cisplatin sensitivity in a concentration-dependent manner in vitro, which could be partially reversed by the knockdown of PPP2R5A (Fig. 6B). Western blot analysis confirmed that PPP2AB56 $\alpha$ in these cells was modulated by miR-218 (Fig. 6C). Taken together, our results revealed that 
A

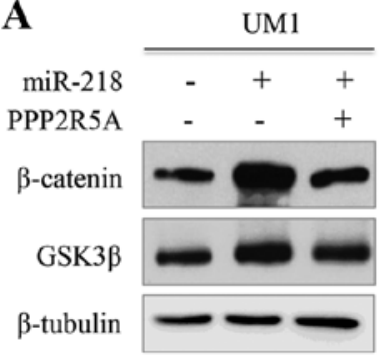

acontrol

口miR-218

-miR-218+PPP2R5A

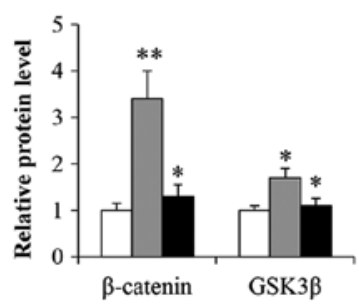

B
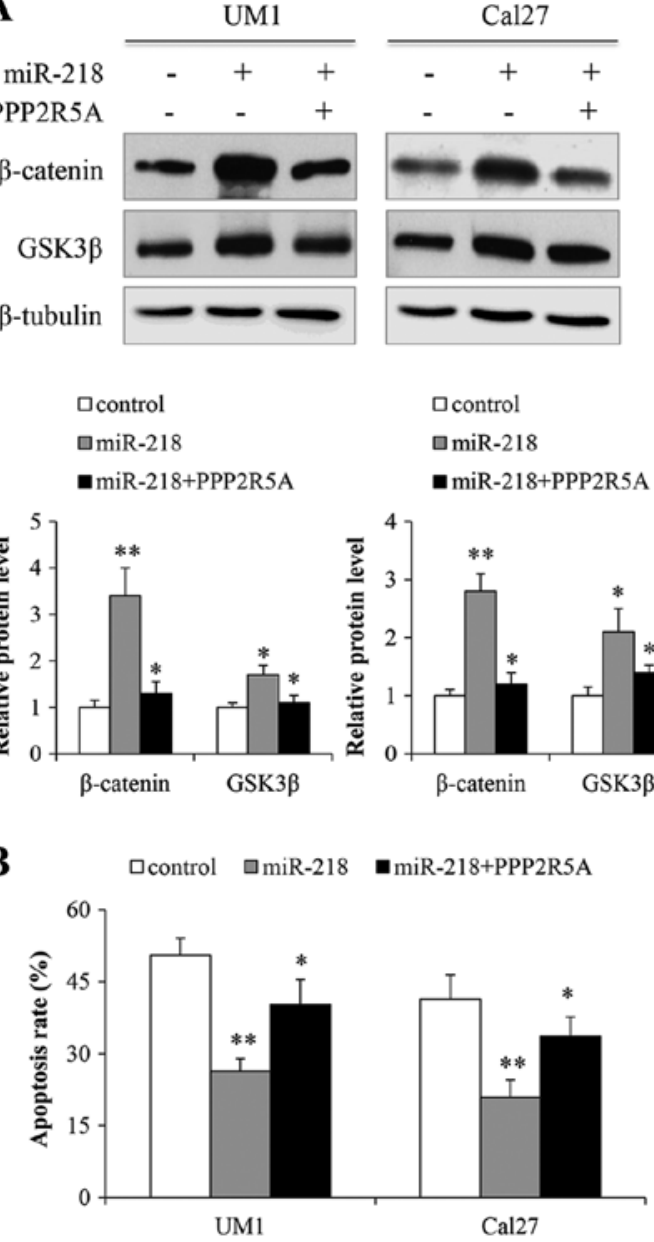

$\square$ control

$\square \mathrm{miR}-218$

- miR-218+PPP2R5A
C

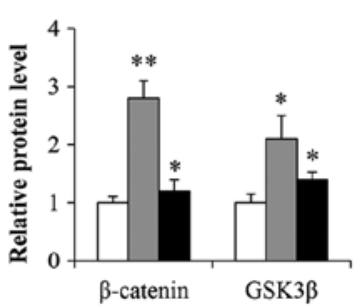

D

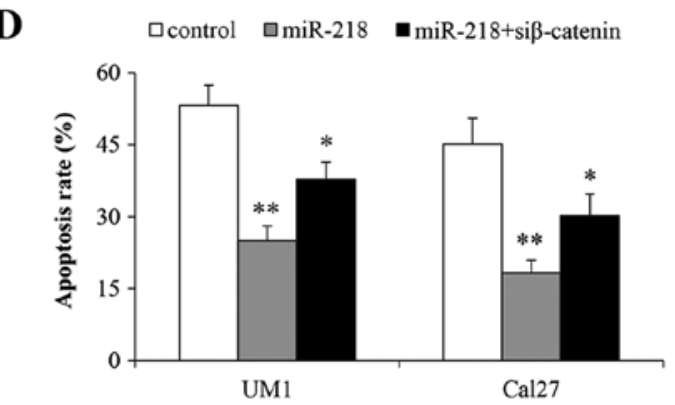

Figure 7. miR-218 activates Wnt signaling in oral cancer cells by inhibiting PPP2R5A. (A) UM1 and Cal27 cells were transfected with miR-218 along with PPP2R5A or its control, and total protein was extracted from the cells for western blot analysis (upper panel). The protein level was quantitated (lower panel). (B) miR-218, PPP2R5A, or the control were transfected into tumor cells in the presence of cisplatin ( $2.5 \mu \mathrm{g} / \mathrm{ml})$. Cell apoptosis was assessed by flow cytometry after $48 \mathrm{~h}$. (C and D) siRNA against $\beta$-catenin suppressed Wnt activation and inhibited the miR-218-induced protection against cell apoptosis. Three independent experiments were performed. Data represent the mean $\pm \mathrm{SD}$ of 3 independent experiments; ${ }^{*} \mathrm{P}<0.05,{ }^{* * *} \mathrm{P}<0.01$.

miR-218 acts as an oncomiR and induces cisplatin resistance in oral cancers by targeting PPP2R5A.

miR-218 targets PPP2R5A, leading to activation of the Wnt signaling pathway. Given that PPP2R5A is a repressor of Wnt signaling, we postulated that miR-218 overexpression in oral cancer cells may play a role in Wnt signaling. In UM1 and Cal27 cells, in which miR-218 is expressed at low levels and Wnt signaling remains inactive, we found that miR-218 overexpression resulted in increased levels of $\beta$-catenin and GSK3 $\beta$ proteins. When the cells were simultaneously transfected with miR-218 and LV-PPP2R5A, $\beta$-catenin protein levels were not affected (Fig. 7A). To determine whether miR-218 impairs cisplatin sensitivity specifically through the Wnt signaling pathway, we transfected UM1 and Cal27 cells with miR-218, miR-218 + LV-PPP2R5A, or a control prior to cisplatin treatment. Results from the flow cytometric analysis showed increased apoptosis of cells transfected with miR-218 + LV-PPP2R5A compared with those transfected with miR-218 (Fig. 7B). Finally, we transfected siRNA against $\beta$-catenin to validate the miR-218-induced Wnt activation. As shown in Fig. 7C and D, miR-218 activated Wnt signaling, whereas the siRNA against $\beta$-catenin abrogated the miR-218-promoting activation of Wnt signaling and cell survival. Collectively, these data indicate that miR-218 may increase cisplatin resistance via the Wnt signaling pathway in oral cancer cells by suppressing PPP2R5A expression.

\section{Discussion}

Resistance to platinum-based chemotherapy is still the major barrier to the treatment of oral cancer. In the present study, we provide evidence of the role of miR-218 in the resistance of oral cancer cells to cisplatin through the Wnt signaling pathway by targeting PPP2R5A. We showed that miR-218 was significantly upregulated in cisplatin-resistant oral cancer cell lines, and in oral cancer patients with failed neoadjuvant chemotherapy. We also demonstrated that miR-218 decreased PPP2R5A levels and increases $\beta$-catenin and GSK3 $\beta$ expression. Importantly, inhibition of miR-218 restored the sensitivity of oral cancer cells to cisplatin therapy. Moreover, sensitivity to cisplatin was partially restored when cells transfected with miR-218 were cotransfected with LV-PPP2R5A or siRNA against $\beta$-catenin compared with the control. Thus, our results 
suggest that miR-218 regulates the cisplatin response of oral cancers through the PPP2R5A/Wnt signaling pathway.

In the present study, UM1 and Cal27 cells, both sensitive to cisplatin, were continuously exposed to a gradient concentration of cisplatin for $\sim 6$ months. The $\mathrm{IC}_{50}$ of UM1cis and Cal27cis cells increased by 7- and 9-fold, respectively, as compared with their parental cell lines. Our results were consistent with the findings of Sun et al (10) and Gosepath et al (31). We also determined the expression levels of chemoresistance-related proteins, including EZH2, ABCG2, MRP1, P-glycoprotein and topoisomerase II $\beta$. These results further identified the resistance to cisplatin of the two resistant cells. To an extent, UM1cis and Cal27cis cells may serve as a tool for further investigation on the molecular mechanism of drug resistance of oral cancer cells.

Various microRNAs (miRNAs) have been demonstrated to regulate the resistance of oral cancer cells to cisplatin, acting as either oncogenes or tumor suppressors (8-10,32-34). Reduced miR-218 has been shown to potentiate the malignant progression of many types of cancers by targeting Robol (12), survivin $(13,18)$, BMI1 (15) and laminin 332 (35). Restoration of the expression of miR-218 was found to reduce the proliferation, migration and invasion and increase the sensitivity of tumor cells to chemotherapeutic agents (20,22). Similarly, decreased expression of miR-218 has also been observed in oral cancers. Patients with lower levels of miR-218 have a higher risk of a poor outcome (19,36,37). However, the activity of miR-218 appears to be functionally different in breast cancer and glioma $(24,25)$. These conflicting data suggest that miR-218 may act as either an oncogene or a tumor suppressor, depending on the tumor type, tumor microenvironment and its targets.

To date, the role of miR-218 in the chemoresistance of oral cancer is not clear. In the present study, we observed a significantly higher expression of miR-218 in chemoresistant oral cancer cells both in vitro and in vivo. Our results are consistent with those obtained in a recent study by Wang et al (26). Given that miRNAs are important molecular regulators in gene expression through the repression of transcription and translation, we further explored the possible biological link between miR-218 and its potential targets. Notably, a total of 7 Wnt-associated genes were predicted to be miR-218 targets by bioinformatic analysis. Of which, a clear association between PPP2R5A and miR-218 expression was identified in oral cancer cells both in vitro and in vivo. Importantly, PPP2R5A was experimentally validated as a direct target of miR-218. Ectopic miR-218 expression or PPP2R5A downregulation reduced cisplatin-induced apoptosis of oral cancer cells. In contrast, inhibition of miR-218 sensitized oral cancer cells to cisplatin, and PPP2R5A sensitized the cells to cisplatin. These results indicated that $\mathrm{miR}-218$ is involved in the regulation of cisplatin resistance in oral cancer.

Aberrant Wnt signaling can promote malignant progression in many epithelial cancers, including oral cancer. Recently, several studies have demonstrated a role for miRNAs in oral cancer via modulation of Wnt pathway components. For example, Shiah et al reported that decreased expression of miR-329 and miR-410, which target a canonical Wnt ligand, Wnt7b, increased $\beta$-catenin activity (38). Moreover, miR-21 promoted $\mathrm{Wnt} / \beta$-catenin signaling activation by directly targeting Dkk2. Decreased miR-21 suppressed the invasive potential of tongue cancer cells with upregulated Dkk2 protein levels (39). In the present study, we found that sensitivity to cisplatin was decreased by upregulation of miR-218. The effects of miR-218 on the chemosensitivity of oral cancer cells may be explained by its indirect activation of Wnt signaling via inhibition of PPP2R5A, which counteracts the inhibitory effects of cisplatin on the same pathway. This notion is supported by the observation that cotransfection of LV-PPP2R5A or administration of the specific siRNA against $\beta$-catenin blocked the effects of miR-218.

MicroRNAs such as miR-218, may exert different biological functions depending on the microenviroment, but the mechanisms are largely unknown. Previous studies have shown decreased expression of miR-218 in human malignancies including oral cancers $(19,36,37)$. Hence, miR-218 may act as a tumor suppressor in these types of cancers. Currently, the role of miR-218 in the chemoresistance of oral cancer is not clear. In the present study, we report that miR-218 promotes cisplatin resistance in oral cancer. We propose several reasons for our inconsistent results. Firstly, miR-218 is an intronic miRNA that is co-expressed with its host genes SLIT2/3 (11). The expression of miR-218 and SLIT2/3 can be regulated via epigenetic mechanisms, such as DNA methylation $(40,41)$. Numerous studies have demonstrated substantial epigenetic alterations in drug-resistant cancer cells (42). Secondly, the oncogene E6 of the high-risk HPV likely contributes to miR-218 expression in cervical and non-small cell lung cancer $(17,43)$. Oral cancer, particularly oropharyngeal cancer, is closely related to HPV infection, which may have an effect on the role of miR-218 in chemoresistance. Finally, the function of miR-218 depends on its targets. An miRNA can affect the expression levels of thousands of genes. Several studies have demonstrated that miR-218 inhibits metastasis via targeting multiple components of the Wnt/ $\beta$-catenin pathway (44). Conversely, miR-218 activates the Wnt pathway by targeting its inhibitors SOST and DKK2, thus, promoting metastasis $(25,45)$. These controversial findings reflect the complexity of miR-218 regulation in cancers. Based on our results, we envision that miR-218-induced Wnt signaling activation may also contribute to its induction of resistance to cisplatin. Nevertheless, we must note that oral tumorigenesis and chemoresistance are complicated processes and involve a variety of regulators. Further studies are needed to determine the precise mechanisms underlying cisplatin resistance in oral cancer.

In summary, we identified miR-218 as an important mediator of the cisplatin response in oral cancer. miR-218 decreased cisplatin sensitivity at least in part through the Wnt signaling pathway in oral cancer by directly targeting PPP2R5A. Based on the potential of miRNA therapy, inhibition of miR-218 may be a therapeutic approach to improve cisplatin sensitivity in oral cancer.

\section{Acknowledgements}

The present study was supported by grants from the National Natural Science Foundation of China (81172567, 81272949, 81202136, 81372885, 81572661 and 81572939), the Major Special Research Collaborative Innovation of Guangzhou (201604020160), and the Pear River S\&T Nova Program of Guangzhou (2014J2200045). 


\section{References}

1. Wang C, Liu XQ, Hou JS, Wang JN and Huang HZ: Molecular mechanisms of chemoresistance in oral cancer. Chin J Dent Res 19: 25-33, 2016

2. Zhang P, Zhang Z, Zhou X, Qiu W, Chen F and Chen W: Identification of genes associated with cisplatin resistance in human oral squamous cell carcinoma cell line. BMC Cancer 6 : 224, 2006.

3. Zhang B, Liu M, Tang HK, Ma HB, Wang C, Chen X and Huang HZ: The expression and significance of MRP1, LRP TOPOII $\beta$, and BCL2 in tongue squamous cell carcinoma. J Oral Pathol Med 41: 141-148, 2012.

4. Olszewski U and Hamilton G: A better platinum-based anticancer drug yet to come? Anticancer Agents Med Chem 10: 293-301, 2010.

5. Donzelli S, Mori F, Biagioni F, Bellissimo T, Pulito C, Muti P Strano S and Blandino G: MicroRNAs: Short non-coding players in cancer chemoresistance. Mol Cell Ther 2: 16, 2014.

6. Garofalo $\mathrm{M}$ and Croce CM: MicroRNAs as therapeutic targets in chemoresistance. Drug Resist Updat 16: 47-59, 2013.

7. Yu ZW, Zhong LP, Ji T, Zhang P, Chen WT and Zhang CP: MicroRNAs contribute to the chemoresistance of cisplatin in tongue squamous cell carcinoma lines. Oral Oncol 46: 317-322, 2010.

8. Ren W, Wang X, Gao L, Li S, Yan X, Zhang J, Huang C, Zhang Y and Zhi K: MiR-21 modulates chemosensitivity of tongue squamous cell carcinoma cells to cisplatin by targeting PDCD4. Mol Cell Biochem 390: 253-262, 2014.

9. Li J, Huang H, Sun L, Yang M, Pan C, Chen W, Wu D, Lin Z, Zeng C, Yao Y, et al: MiR-21 indicates poor prognosis in tongue squamous cell carcinomas as an apoptosis inhibitor. Clin Cancer Res 15: 3998-4008, 2009.

10. Sun L, Yao Y, Liu B, Lin Z, Lin L, Yang M, Zhang W, Chen W, Pan C, Liu Q, et al: MiR-200b and miR-15b regulate chemotherapy-induced epithelial-mesenchymal transition in human tongue cancer cells by targeting BMI1. Oncogene 31: 432-445, 2012.

11. Tatarano S, Chiyomaru T, Kawakami K, Enokida H, Yoshino H, Hidaka H, Yamasaki T, Kawahara K, Nishiyama K, Seki N, et al miR-218 on the genomic loss region of chromosome 4p15.31 functions as a tumor suppressor in bladder cancer. Int J Oncol 39: 13-21, 2011

12. Tie J, Pan Y, Zhao L, Wu K, Liu J, Sun S, Guo X, Wang B Gang Y, Zhang Y, et al: MiR-218 inhibits invasion and metastasis of gastric cancer by targeting the Robol receptor. PLoS Genet 6: e1000879, 2010

13. Alajez NM, Lenarduzzi M, Ito E, Hui AB, Shi W, Bruce J, Yue S, Huang SH, Xu W, Waldron J, et al: MiR-218 suppresses nasopharyngeal cancer progression through downregulation of survivin and the SLIT2-ROBO1 pathway. Cancer Res 71: 23812391, 2011.

14. Venkataraman S, Birks DK, Balakrishnan I, Alimova I, Harris PS, Patel PR, Handler MH, Dubuc A, Taylor MD, Foreman NK, et al: MicroRNA 218 acts as a tumor suppressor by targeting multiple cancer phenotype-associated genes in medulloblastoma. J Biol Chem 288: 1918-1928, 2013.

15. Tu Y, Gao X, Li G, Fu H, Cui D, Liu H, Jin W and Zhang Y: MicroRNA-218 inhibits glioma invasion, migration, proliferation, and cancer stem-like cell self-renewal by targeting the polycomb group gene Bmi1. Cancer Res 73: 6046-6055, 2013.

16. Mathew LK, Skuli N, Mucaj V, Lee SS, Zinn PO, Sathyan P, Imtiyaz HZ, Zhang Z, Davuluri RV, Rao S, et al: $m i R-218$ opposes a critical RTK-HIF pathway in mesenchymal glioblastoma. Proc Natl Acad Sci USA 111: 291-296, 2014.

17. Wu DW, Cheng YW, Wang J, Chen CY and Lee H: Paxillin predicts survival and relapse in non-small cell lung cancer by microRNA-218 targeting. Cancer Res 70: 10392-10401, 2010.

18. Kogo R, How C, Chaudary N, Bruce J, Shi W, Hill RP, Zahedi P, Yip KW and Liu FF: The microRNA-218 Survivin axis regulates migration, invasion, and lymph node metastasis in cervical cancer. Oncotarget 6: 1090-1100, 2015.

19. Wu DW, Chuang CY, Lin WL, Sung WW, Cheng YW and Lee H: Paxillin promotes tumor progression and predicts survival and relapse in oral cavity squamous cell carcinoma by microRNA-218 targeting. Carcinogenesis 35: 1823-1829, 2014

20. Xie J, Yu F, Li D, Zhu X, Zhang X and Lv Z: MicroRNA-218 regulates cisplatin (DPP) chemosensitivity in non-small cell lung cancer by targeting RUNX2. Tumour Biol 37: 1197-1204, 2016 .
21. Tian H, Hou L, Xiong YM, Huang JX, She YJ, Bi XB and Song XR: miR-218 suppresses tumor growth and enhances the chemosensitivity of esophageal squamous cell carcinoma to cisplatin. Oncol Rep 33: 981-989, 2015.

22. Zarogoulidis P, Petanidis S, Kioseoglou E, Domvri K, Anestakis D and Zarogoulidis K: MiR-205 and miR-218 expression is associated with carboplatin chemoresistance and regulation of apoptosis via Mcl-1 and Survivin in lung cancer cells. Cell Signal 27: 1576-1588, 2015

23. Zanette DL, Rivadavia F, Molfetta GA, Barbuzano FG, ProtoSiqueira R, Silva-Jr WA, Falcão RP and Zago MA: miRNA expression profiles in chronic lymphocytic and acute lymphocytic leukemia. Braz J Med Biol Res 40: 1435-1440, 2007.

24. Feng Z, Zhang L, Zhou J, Zhou S, Li L, Guo X, Feng G, Ma Z, Huang $W$ and Huang F: mir-218-2 promotes glioblastomas growth, invasion and drug resistance by targeting CDC27. Oncotarget 8: 6304-6318, 2017.

25. Hassan MQ, Maeda Y, Taipaleenmaki H, Zhang W, Jafferji M, Gordon JA, Li Z, Croce CM, van Wijnen AJ, Stein JL, et al: miR-218 directs a Wnt signaling circuit to promote differentiation of osteoblasts and osteomimicry of metastatic cancer cells. J Biol Chem 287: 42084-42092, 2012

26. Wang S, Su X, Bai H, Zhao J, Duan J, An T, Zhuo M, Wang Z, $\mathrm{Wu}$ M, Li Z, et al: Identification of plasma microRNA profiles for primary resistance to EGFR-TKIs in advanced non-small cell lung cancer (NSCLC) patients with EGFR activating mutation. J Hematol Oncol 8: 127, 2015.

27. Wlodarchak $\mathrm{N}$ and Xing Y: PP2A as a master regulator of the cell cycle. Crit Rev Biochem Mol Biol 51: 162-184, 2016.

28. Kumar A, Pandurangan AK, Lu F, Fyrst H, Zhang M, Byun HS, Bittman R and Saba JD: Chemopreventive sphingadienes downregulate Wnt signaling via a PP2A/Akt/GSK3 $\beta$ pathway in colon cancer. Carcinogenesis 33: 1726-1735, 2012.

29. Mitra A, Menezes ME, Pannell LK, Mulekar MS, Honkanen RE, Shevde LA and Samant RS: DNAJB6 chaperones PP2A mediated dephosphorylation of GSK $3 \beta$ to downregulate $\beta$-catenin transcription target, osteopontin. Oncogene 31: 4472-4483, 2012.

30. Liu X, Wang C, Chen Z, Jin Y, Wang Y, Kolokythas A, Dai Y and Zhou X: MicroRNA-138 suppresses epithelial-mesenchymal transition in squamous cell carcinoma cell lines. Biochem J 440: 23-31, 2011

31. Gosepath EM, Eckstein N, Hamacher A, Servan K, von Jonquieres G, Lage H, Györffy B, Royer HD and Kassack MU: Acquired cisplatin resistance in the head-neck cancer cell line Cal27 is associated with decreased DKK1 expression and can partially be reversed by overexpression of DKK1. Int J Cancer 123: 2013-2019, 2008.

32. Liu M, Wang J, Huang H, Hou J, Zhang B and Wang A: miR-181a-Twist1 pathway in the chemoresistance of tongue squamous cell carcinoma. Biochem Biophys Res Commun 441 364-370, 2013.

33. Zhou X, Ren Y, Liu A, Jin R, Jiang Q, Huang Y, Kong L, Wang X and Zhang L: WP1066 sensitizes oral squamous cell carcinoma cells to cisplatin by targeting STAT3/miR-21 axis. Sci Rep 4: 7461, 2014.

34. Peng F, Zhang H, Du Y and Tan P: miR-23a promotes cisplatin chemoresistance and protects against cisplatin-induced apoptosis in tongue squamous cell carcinoma cells through Twist. Oncol Rep 33: 942-950, 2015.

35. Kinoshita T, Hanazawa T, Nohata N, Kikkawa N, Enokida H, Yoshino H, Yamasaki T, Hidaka H, Nakagawa M, Okamoto Y, et al: Tumor suppressive microRNA-218 inhibits cancer cell migration and invasion through targeting laminin-332 in head and neck squamous cell carcinoma. Oncotarget 3: 1386-1400, 2012.

36. Peng SC, Liao CT, Peng CH, Cheng AJ, Chen SJ, Huang CG, Hsieh WP and Yen TC: MicroRNAs MiR-218, MiR-125b, and Let-7g predict prognosis in patients with oral cavity squamous cell carcinoma. PLoS One 9: e102403, 2014.

37. Jamali Z, Asl Aminabadi N, Attaran R, Pournagiazar F, Ghertasi Oskouei S and Ahmadpour F: MicroRNAs as prognostic molecular signatures in human head and neck squamous cell carcinoma: A systematic review and meta-analysis. Oral Oncol 51: 321-331, 2015.

38. Shiah SG, Hsiao JR, Chang WM, Chen YW, Jin YT, Wong TY, Huang JS, Tsai ST, Hsu YM, Chou ST, et al: Downregulated miR329 and miR410 promote the proliferation and invasion of oral squamous cell carcinoma by targeting Wnt-7b. Cancer Res 74: 7560-7572, 2014. 
39. Kawakita A, Yanamoto S, Yamada S, Naruse T, Takahashi H, Kawasaki $\mathrm{G}$ and Umeda M: MicroRNA-21 promotes oral cancer invasion via the $\mathrm{Wnt} / \beta$-catenin pathway by targeting DKK2. Pathol Oncol Res 20: 253-261, 2014.

40. Dickinson RE, Dallol A, Bieche I, Krex D, Morton D, Maher ER and Latif F: Epigenetic inactivation of SLIT3 and SLIT1 genes in human cancers. Br J Cancer 91: 2071-2078, 2004.

41. Narayan G, Goparaju C, Arias-Pulido H, Kaufmann AM, Schneider A, Dürst M, Mansukhani M, Pothuri B and Murty VV: Promoter hypermethylation-mediated inactivation of multiple Slit-Robo pathway genes in cervical cancer progression. Mol Cancer 5: 16, 2006.

42. Roberti A, La Sala D and Cinti C: Multiple genetic and epigenetic interacting mechanisms contribute to clonally selection of drugresistant tumors: Current views and new therapeutic prospective. J Cell Physiol 207: 571-581, 2006.
43. Martinez I, Gardiner AS, Board KF, Monzon FA, Edwards RP and Khan SA: Human papillomavirus type 16 reduces the expression of microRNA-218 in cervical carcinoma cells. Oncogene 27: 2575-2582, 2008.

44. Iwai S, Yonekawa A, Harada C, Hamada M, Katagiri W, Nakazawa $M$ and Yura Y: Involvement of the Wnt- $\beta$-catenin pathway in invasion and migration of oral squamous carcinoma cells. Int J Oncol 37: 1095-1103, 2010.

45. Zhang WB, Zhong WJ and Wang L: A signal-amplification circuit between miR-218 and $\mathrm{Wnt} / \beta$-catenin signal promotes human adipose tissue-derived stem cells osteogenic differentiation. Bone 58: 59-66, 2014. 